\title{
FORMAÇÃO, PESQUISA E EXTENSÃO NA EDUCAÇÃO PROFISSIONAL E TECNOLÓGICA: REDE NACIONAL DE LABORATÓRIOS DE IMPRESSÃO 3D NO SUS
}

\section{Luciana Castaneda ${ }^{1}$}

\section{Resumo}

A presente comunicação apresenta as ações em desenvolvimento da 3DSUS Rede Nacional de Pesquisa e Extensão Tecnológica de Laboratórios de Impressão 3D no SUS. As ações de transferência de tecnologia de Fabricação Aditiva (Impressão 3D) são desenvolvidas como resultado de estratégias de ensino em espaços não-formais da Educação Profissional e Tecnológica. Tem como público-alvo os trabalhadores do SUS do componente da Atenção Especializada do SUS, Oficinas Ortopédicas. A ação emergencial em andamento tem se dado em conjunto com três Instituições de Ciência e Tecnologia (ICT) e duas Oficinas Ortopédicas. As atividades em andamento são uma pequisa-ação de Ensino-Serviço para o Desenvolvimento de Produto, a Engenharia de Tecidos e a Educação Permanente em Saúde e buscam alcançar representatividade nacional. Envolvem ações em Rede de Pesquisa e Inovação para: 1) Prototipação Rápida de insumos e componentes para o enfrentamento a COVID 19 por Fabricação Aditiva (Impressão 3d), 2) Testagem de insumos e componentes para a produção emergencial de Equipamentos de Proteção Individual (EPI) por manufatura tradicional, e 3) Qualificação Profissional dos trabalhadores do SUS para o manuseio de tecnologias de Manufatura Avançada.

Palavras-chave: Atividades Científicas e Tecnológicas, Desenho Assistido por Computador, Sistema Único de Saúde, Fração Assistencial Especializada,

\section{Abstract}

This communication presents as actions in the development of 3DSUS - National Network of Research and Technological Extension of 3D Printing Laboratories in

\footnotetext{
${ }^{1}$ Instituto Federal do Rio de Janeiro, IFRJ - campus Mesquita. E-mail: luciana.ribeiro@ifrj.edu.br
} 
SUS. Additive Manufacturing technology transfer actions (3D printing) are carried out as a result of teaching strategies in spaces not formed by Professional and Technological Education. Its target audience is SUS workers from the SUS Specialized Care component, Orthopedic Workshops. Emergency action in progress has taken place together with three science and technology institutions (ICT) and two orthopedic workshops. As ongoing activities, it is a small teaching action for the Product Development Service, Tissue Engineering, and Permanent Education in Health and Seeking to achieve national representativeness. Involve steps in the Research and Innovation Network to 1) Rapid prototyping of inputs and components to face COVID 19 by Additive Manufacturing (3d printing), 2) Testing of information and parts for emergency production of Personal Protective Equipment (PPE) by traditional manufacturer, and 3) Professional qualification of SUS workers to handle advanced manufacturing technologies.

Key-words: Scientific and Technical Activities, Computer-Aided Design, Unified Health System, Specialized Care Fraction

\section{Contextualização}

A pandemia da COVID 19 evidenciou a sociedade grandes dificuldades dos sistemas de saúde na prevenção, tratamento e mitigação do impacto causado por doenças infecciosas virais altamente contagiosas. A globalização, a negligência, o descrédito nas informações cientificas além do intenso fluxo migratório propiciaram a disseminação do vírus em uma escala nunca antes vista. Até o final de Abril, são 2.8 milhões de casos e quase 200.000 mortes mundialmente ${ }^{1}$.

No Brasil, a pandemia avança e revela profundos aspectos de iniquidades geográficas e sociais em saúde. Os dados do Ministério da Saúde para o dia 25.04.2020, revelam cerca de 58.000 casos da doença e 4.016 óbitos confirmados. No ritmo de evolução da pandemia, a cada 24 horas nota-se um incremento de $10 \%$ no número de casos e óbitos confirmados pela COVID $19^{2}$. 
Somado ao panorama de alta transmissibilidade sustentada em cidades como São Paulo, Rio de Janeiro, Manaus, Fortaleza observa-se uma baixa capacidade de testagem dos indivíduos sintomáticos. A baixa capacidade do sistema de saúde para testar os casos suspeitos pode levar a maior dificuldade de superação da pandemia, uma vez que a não identificação e localização dos casos suspeitos contribuem para a continuidade da transmissão sustentada.

O fornecimento limitado de máscaras de respiração N95, protetores faciais, válvulas de ventilador, kits de teste e outros equipamentos de proteção individual. Assim, produção e distribuição adequadas tem sido crítica durante esta pandemia. Para colaborar na solução desses problemas, a Fabricação Aditiva por Impressão Tridimensional (3D), tem sido utilizada de forma inovadora ${ }^{3}$. Seja na produção de EPI, na proposição de swabs nasofaríngeos e orofaríngeos de polímero flexível ou na produção de válvulas de ventiladores mecânicos, a impressão 3D é apontada como potencialmente promissora como tecnologia adjuvante ao enfrentamento da COVID 19.

Posto as dificuldades que o sistema de saúde brasileiro tem passado e passará nos próximos meses, há que se pensar em estratégias que possibilitem o aumento da capacidade de resposta dos serviços do Sistema Único de Saúde nos seus diferentes níveis de atenção. Foi nesse contexto de pronta resposta a uma emergência de saúde pública, que a Rede Nacional de Laboratórios de Impressão 3D no SUS foi criada.

Contando com a parceria ensino-serviço de duas Oficinas Ortopédicas e três Instituições de Ciência e Tecnologia (IcTs), a atuação da Rede tem se dado na produção emergencial de Equipamentos de Proteção Individual e em atividades de pesquisa que envolvem a prototipação rápida de componentes e insumos prioritários. Atualmente, a Rede conta com quatro (4) polos de pesquisa no Rio de Janeiro e um (1) no estado do Amazonas. Conta também com dois polos de produção nas Oficinas Ortopédicas do SUS, um (1) no estado de Goiás e um (1) no estado de São Paulo.

E, porque, a escolha das Oficinas Ortopédicas como eixo de transferência da tecnologia? Destacam-se as Oficinas Ortopédicas do SUS como ponto de atenção com capacidade de resposta e contribuição para o enfrentamento a 
COVID 19. A Oficina Ortopédica é um espaço fabril e uma unidade de transformação da Atenção Especializada em Reabilitação custeada pelo Ministério da Saúde via incentivo de teto financeiro da Média e Alta Complexidade. Seu incentivo é transferido pelo Governo Federal fundo a fundo anualmente, totalizando investimento público da ordem de $R \$ 648.000,00$. A contratualização do ponto de atenção com o SUS possui portaria específica de consolidação. A Oficina é um dos componentes de média complexidade em reabilitação do SUS. Participa do processo de cuidado centrado nos usuários e realiza de maneira adjuvante a decisão e produção de produtos assistivos de Órteses, Próteses e Meios Auxiliares de Locomoção4.

No contexto da prevenção e do controle da COVID 19 tem potencial para aumentar a capacidade de resposta do SUS e para o SUS. As Oficinas Ortopédicas não só podem, como devem atuar no combate e mitigação da pandemia pela produção, desenvolvimento e prototipação de EPI e componentes de respiradores mecânicos. Por ser estrutura fabril e unidade de transformação com ampla experiencia em atividades que envolvem o termoplástico e a solda, a Oficina, pode ser utilizada como capacidade instalada para o SUS e para a sociedade no enfrentamento a Pandemia. Em um contexto emergencial, tem enorme potencial para serem incrementados para Laboratórios de Impressão 3D no SUS. E é sobre esse potencial de incremento tecnológico que a presente comunicação versa.

Nas Oficinas Ortopédicas já existe Capacidade Instalada para manuseio de termoplásticos, além de recursos humanos da Educação Profissional em Saúde com habilidade para a Manufatura. Embora a Manufatura não seja o método de eleição para a produção de insumos e componentes de EPI e respiradores mecânicos em escala industrial, a dependência do mercado externo e a concorrência em busca do produto, justificam a elaboração de arranjos colaborativos como o aqui elencado.

A perspectiva das IcTs é transferir tecnologia para a estruturação emergencial de Laboratórios de Impressão 3D no SUS e para o SUS, tendo a Oficina Ortopédica como lócus de atuação. O contexto do objeto de pesquisa e extensão tecnológica é a criação de estratégias que visem mitigar a escassez 
de EPls e componentes de respiradores mecânicos e que atualmente representam um enorme desafio para o SUS e para a sociedade imposto pela chegada do COVID-19. O pano de fundo é que as unidades de saúde estão tendo dificuldades para acessar os insumos necessários de EPI e as unidades atenção hospitalar e hospitais de campanha precisam e precisarão também atender a demanda elevada por ventilação mecânica.

O desenho das estratégias de otimização, contingência e crise para a dispensação e oferta de EPI que serão traçados por Plano de Ação local dos Laboratórios de Impressão 3D no SUS, oferecerão capacidade de resposta da Atenção Especializada em Saúde quando as opções para uso dos suprimentos estiverem estressadas, com pouca carga ou ausente. Os produtos dispensados possibilitarão colaborar para as estratégias de contingência pela produção local quando houver escassez. Também podem colaborar, se as instalações prioritárias tiverem suprimentos suficientes agora, mas provavelmente acabarem em breve. Já as estratégias de crise podem ser estruturadas nos laboratórios de impressão 3D no SUS quando consideradas a severa escassez de insumos e componentes prioritários. Devem ser as opções de contingência para ajudar a ampliar os suprimentos disponíveis para as necessidades mais críticas. $E$, no caso, de nenhum EPI comercial estar disponível, há que se considerar cuidadosamente as abordagens alternativas que os laboratórios podem oferecer ao sistema de saúde local.

São as Oficinas, lócus estratégicos no Território brasileiro que podem e devem ser qualificadas para o incremento tecnológico das tecnologias já desenvolvidas pelas IcTs envolvidas com a Fabricação Aditiva (Impressão 3d). O diferencial da proposta é a possibilidade de atuação em rede nacional de Laboratórios de Impressão 3D no SUS para a prototipação rápida, prova de conceito e dispensação de EPI e componentes de respiradores mecânicos utilizando as Oficinas Ortopédicas da Atenção Especializada como ambiente fabril e de unidade de transformação. Os produtos já desenvolvidos pelas Oficinas, terão incremento tecnológico visando estratégias de contingência para maior durabilidade, limpeza repetida e desinfecção, segurança e a efetividade com potencial de incorporação simplificada pelos demais níveis de atenção a 
saúde do SUS. A relevância do projeto se dá pelo recorte nacional em rede de colaboração e pela parceria ensino-serviço entre o Instituto Federal de Educação Ciência e Tecnologia do Rio de Janeiro (IFRJ), a Universidade Federal do Amazonas (UFAM), o Instituto Nacional de Tecnologia (INT) e as Oficinas Ortopédicas do SUS. A formação em serviço proposta irá contribuir para a qualificação profissional sobre Manufatura Avançada para os trabalhadores do SUS no componente da Atenção Especializada em Saúde, e compõe o foco estratégico na Educação Profissional e Tecnológica.

\section{Objetivos da Rede Nacional de Laboratórios de Impressão 3D no SUS}

Estruturar Laboratórios de Impressão 3D no componente de Atenção Especializada do SUS para o desenvolver, prototipar e dispensar insumos prioritários e componentes de respiradores mecânicos por métodos de Manufatura Aditiva (Impressão 3D) e Manufatura Tradicional.

As Metas são: a) Identificar os EPI e componentes de respiradores mecânicos com potencial de convergência tecnológica de Manufatura Avançada e Tradicional e com possibilidade de produção pelos Laboratórios de Impressão 3D do SUS. B) Caracterizar a Capacidade Instalada do componente fabril das Oficinas Ortopédicas do SUS com potencial para a produção por Manufatura Avançada. C) Implementar incremento tecnológico ao componente fabril das Oficinas Ortopédicas do SUS pela Manufatura Aditiva e Transformação Digital. D) Desenvolver produtos de EPI e componentes de respiradores mecânicos. E) Contribuir para a capacidade de resposta do componente da Atenção Especializada em Saúde no enfrentamento a COVID 19. F) Dispensar localmente produtos produzidos pelos Laboratórios de Impressão 3D do SUS de acordo com as necessidades epidemiológicas do Território.

Os produtos que serão gerados pelas atividades de Pesquisa e Extensão Tecnológica da Rede são: a) Lista de tecnologias identificadas para a produção por Manufatura Avançada e Tradicional; b) Inventário das Oficinas participantes da Rede; c) Concluintes do curso de Qualificação Profissional sobre Manufatura 
Aditiva e suas aplicações para a produção de EPI pelas Oficinas Ortopédicas do SUS; d) Ficha técnica dos produtos prioritários a serem produzidos; e) Quantitativo de produtos dispensados estratificados por região, estado, macrorregião de saúde, e nível do componente de atenção em saúde.

\section{Como a Rede atua?}

A Rede atua por transferência de tecnologia da lct para a Oficina Ortopédica e vice-versa. O esforço é concentrado na Convergência Tecnológica e na potencialização das ações com maior alcance geográfico possível. A meta da Rede é a entrega de Kits de Convergência Tecnológica para estruturação de Laboratórios de Impressão 3D no SUS. Trata-se de uma Rede Colaborativa para incremento científico com atividades de Extensão Tecnológica e Formação em espaços não formais. Se insere na Prevenção e no Controle da COVID 19 tendo como cenário de atuação, o ambiente fabril e unidade de transformação do SUS. O método de pesquisa é a pesquisa-ação. As atividades envolvem três ciclos

Ciclo I (Pesquisa). a) Plano de Ação dos Laboratórios de Impressão 3D, b) Implementação da infraestrutura e c) Avaliação do ciclo de vida das tecnologias empregada para a produção dos EPI e componentes de respirador mecânicos nos Laboratórios de Impressão 3D do SUS com representatividade de pelo menos uma Oficina em cada região do país.

Ciclo II (Formação em espaços não-formais de Ensino). a) Formação de Recursos Humanos em Saúde. A formação em EAD será realizada em acompanhamento das IcTs que irão produzir recursos didáticos de Educação Continuada para a produção local nos Laboratórios de Impressão 3D. A Qualificação Profissional para o manuseio de tecnologias de Fabricação Aditiva e Transformação Digital terão como tema o desenvolvimento de produtos e componentes aprimorados pela convergência tecnológica com a Manufatura Tradicional. Nessa etapa será realizada a intervenção formativa para os trabalhadores do SUS.

Ciclo III (Extensão Tecnológica). a) Desenvolvimento e dispensação de produtos prioritários, prototipagem rápida e prova de Conceito. 
Quadro 1. Etapas dos ciclos de atuação da Rede Nacional de Laboratórios de Impressão 3D no SUS.

\section{Etapas}

a) Mapeamento das necessidades locais e da capacidade instalada

b) Estruturação do ambiente Fabril e formação de recursos humanos

c) Identificação de convergências tecnológicas de Manufatura e produção local de acordo com as necessidades epidemiológicas locais do Território

d) Elaboração de itinerários de formação sobre tecnologias de Manufatura Aditiva e suas aplicações na Atenção Especializada em Saúde

\section{Resultados esperados}

Os resultados esperados são o de atuação em Rede nacional de enfrentamento a COVID 19. Por estratégia de mitigação do impacto da pandemia e pela atuação na redução do número de infectados os resultados esperados se concentram. A contribuição cientifica de convergência tecnológica da manufatura tradicional com manufatura aditiva em espaços de fábrica já instalados no SUS e custeados diretamente pelo Ministério da saúde irão fortalecer a capacidade de contribuição do componente especializado do sistema público de saúde. A produção emergencial de EPI contribuirá para a proteção contra exposições ao COVID-19 que não podem ser eliminadas ou reduzidas por outras medidas. Os trabalhadores no cenário de atuação hospitalar precisam usar luvas, capotes e proteção facial/ocular além das máscaras de proteção. Esses produtos divididos em Alto potencial de exposição e Baixo potencial de exposição, são as soluções esperadas do projeto de 
pesquisa. Também são esperados a capacidade de transformação digital e prototipagem rápida de componentes de respirador mecânico

No desenvolvimento dos produtos serão identificadas técnicas e tecnologias passiveis de produção e desenvolvimento tecnológico no ambiente fabril das Oficinas Ortopédicas transformada em Laboratórios de Impressão 3D. O cronograma de entrega anual para os demais serviços do SUS visa a dispensação de EPI de acordo com a demanda do território e o sistema de regulação e são eles: a) Escudos Faciais, b) Protótipo Técnico da máscara respirador com elemento filtrante, c) Capote com sistema de vedação, d) Máscaras cirúrgicas reutilizáveis, e) Adaptadores para maior conforto no uso das máscaras faciais, f) Óculos de proteção e g) componentes de respiradores mecânicos.

Os beneficiários das soluções esperadas produzidas e testadas são os profissionais envolvidos com a Prevenção, Manejo e Controle do COVID e os usuários do SUS. Serão orientadas pelas IcTs, estratégias para dispensação local nos territórios mediante Plano de Ação. As estratégias de aprimoramento tecnológico da produção por Manufatura Avançada irão contribuir para a proposição de soluções que utilizem a capacidade instalada da atenção especializada para o Plano Emergencial de combate a COVID 19.

\section{Considerações Finais}

A criação de Laboratórios de Impressão 3D no SUS espalhados nacionalmente e a Qualificação Profissional dos trabalhadores da Oficina Ortopédica para a produção e prototipagem de insumos e componentes prioritários para o enfrentamento a COVID 19 de acordo com as demandas epidemiológicas do Território são importantes contribuições cientificas e tecnológicas identificadas no recorte aqui fomentado. Os produtos gerados pela implementação de Polos da Rede Nacional de Pesquisa e Extensão Tecnológica de Laboratórios de Impressão 3D no SUS irão atender as demandas locais que a pandemia impõe e podem ser potencialmente ampliados para as demais Oficinas Ortopédicas do SUS.A infraestrutura para realização das atividades conta com a Capacidade Instalada de duas Oficinas Ortopédicas do SUS. A 
expansão da Rede dependerá da captação de novos recursos e arranjos e a expectativa é alcançar nos próximos dois meses alcance nacional no território brasileiro.

\section{Referências Bibliográficas}

1. COVID-19 Dashboard by the Center for Systems Science and Engineering (CSSE) at Johns Hopkins University (JHU). Disponivel em : https://coronavirus.jhu.edu/map.html Acessado em 26.04.2020

2. Brasil. Ministério da Saude. Disponivel em:

https://www.saude.gov.br/noticias/agencia-saude/46789-coronavirusbrasil-registra-58-509-casos-e-4-016-mortes Acessado em 26.04.2020

3. Ishack S, Lipner SR.Applications of 3D Printing Technology to Address COVID-19 Related Supply Shortages. Am J Med. 2020 Apr 21. pii: S00029343(20)30332-6. doi: 10.1016/j.amjmed.2020.04.002. [Epub ahead of print]

4. Guia para Prescrição, Concessão, Adaptação e Manutenção de Órteses, Próteses e Meios Auxiliares de Locomoção / Ministério da Saúde, Secretaria de Atenção Especializada à Saúde, Departamento de Atenção Especializada e Temática. - Brasília: Ministério da Saúde, 2019. Disponivel em:

https://bvsms.saude.gov.br/bvs/publicacoes/guia manutencao orteses proteses auxiliares locomocao.pdf Acessado em 26.04.2020 